\title{
Investigating Students' Attitudes towards Pedagogical Dictionaries: A Study of Sudanese English Majors
}

\author{
Dr. Nauman Al Amin Ali Al Sayed \\ Assistant Professor \\ University of Khartoum, Sudan \\ Shaqra University \\ Saudi Arabia \\ Dr. Ahmed Gumaa Siddiek \\ Shaqra University \\ Former Head of English Department \\ Al-Zaeem Al-Azhari University \\ Sudan
}

\begin{abstract}
This study attempts to uncover the overall perceptions and actual dictionary practices among a sample of 160 Sudanese English majors. A questionnaire based on Bejoint's (1981) classic study, with more recent modifications such as Hartmann (2005), is utilized. Results indicate that students are overwhelmingly aware of the crucial role of dictionaries in language learning. Also, while most of the subjects are convinced of the superiority of advanced paper- based monolingual dictionaries, they almost as frequently refer to the more accessible electronic and bilingualized dictionaries. Yet, on the whole, dictionary use is limited and is almost invariably associated with reading rather than productive language skills. More significantly, in tandem with earlier studies, the subjects of the present study employ the (monolingual) dictionary primarily as a decoding tool to locate definitions, to the almost utter neglect of such vital entry components as pronunciation, collocations and level of usage. Finally, the subjects manifest a marked lack of knowledge, both of ancillary dictionary matter such as appendices and abbreviations and the organization of definitions in the main dictionary entry. It is suggested that such ignorance is largely due to the exclusion of lexicography from university syllabi and teaching practices in Sudanese universities.
\end{abstract}

Keywords: EFL, Sudan. Lexicography, Monolingual Dictionary, Entry, Definition, Decoding, Encoding

\subsection{Introduction}

Ever since their inception in the $18^{\text {th }}$ century in the work of Samuel Johnson (1747) up to the colossal editions of Oxford English Dictionary in the mid- $20^{\text {th }}$ century, English dictionaries have been regarded as the ultimate authority on language This has been to such a degree that a desk dictionary is referred to as a Book; hence invoking the Bible and an aura of reverence. The indication of hallowedness has changed little with the development of pedagogical monolingual lexicography in the volumes of Michael West (1935) and, more substantially, Oxford Advanced Learners' Dictionary (1948) and Longman Dictionary of Contemporary Dictionary (1978), among others. On the other hand, the rise of learner- centered theories has paved the way for the production of dictionaries tailored for the needs of beginner and elementary levels as well as the popularity of bilingual, electronic and bilingualized dictionaries that render definitions in both the source and target languages.

English EFL lexicography (our main focus in this paper) has changed beyond recognition in the last three decades and is now a flourishing field of foreign language acquisition for three main reasons. First, there has been a renewed interest in the nature of the lexicon and vocabulary acquisition features invariably linked to dictionaries (e.g. Lewis, 1997; Nation, 2001; Schmitt, 2007). Second, simultaneous with the interest in vocabulary, there has been a huge advance in compilation and analysis of written and spoken corpora through the tools of computational linguistics (e.g. Sinclair,(1995), both easing the anecdotal labor of traditional lexicographers and resulting in the production of dictionaries based on frequencies of authentic language use. 
The new insights are best manifested in corpus- based dictionaries such as the Collins- COBUILD enterprise. Thirdly, as has been cogently demonstrated by Crystal (2003), English has become a truly global language and that in our ever shrinking and interdependent world, the hegemony of English as a medium of written and oral communication can hardly be disputed. Consequently, people with ambitions to advance themselves will strive to learn English, and, naturally enough, dictionaries come in the picture, as they provide the most explicit and exhaustive description of language.

Dictionaries are regarded by many as the repository of final linguistic authority (Wright, 2001) and a bank account of words to be drawn upon in time of need. A dictionary is the first thing an EFL student buys and students carry dictionaries, not grammar textbooks (Baxter, 1980) and EFL students could have a powerful tool at their disposal, which they can use to attain a deeper understanding of the use of a new language situation which can enable them to have accurate production and comprehension. Hence, a dictionary serves as a means whose purpose is to provide information about language which can be applied to a variety of activities. A successful dictionary will show students the possibilities of language and is capable of providing a wealth of information on spelling, grammatical and morphological information, definitions, collocation, etymology, and level of use and language varieties (Atkins, 1985). However, being able to use a dictionary is obviously not an end in itself; we use it, according to Stein (2002:11), in order to understand what someone has said, or what we are reading, or to be able to express what we want to say. In short, a dictionary is an aid to understanding.

That the dictionary is an essential learning tool is being increasingly acknowledged (Hartmann, 1999). However, other researchers such as Garcia (2005) noted that the spate of dictionary production has not been matched by an adequate research into the type of users and language skills needed for the exploitation of dictionaries. In the same vein, , Atkinson (1998) points out that out of the four EFL dictionary research areas, namely history, typology, criticism and users, the last has only begun to be addressed, mainly as an off-shoot of learner- centred theories. This is essential if EFL students are to realize their potentials and if EFL dictionaries are to be tapped for maximum benefit.

\subsection{Statement of the Problem}

According to Stein (2002), no account of dictionaries is complete without noting the user, his needs, his expectations, and his prejudices. Much of the investigation on lexicography has focused on the suitability of information found in dictionary entries, so determining what information should be included in these works and how this should be presented is very important. The issue so far has been how dictionaries can teach students rather than on how students can learn from it. Such a tendency is critiqued by Hartmann's (1991) viewpoint that, ultimately; all dictionaries are motivated by and judged against the lexical needs of the language users whom they serve. Then, it is no wonder, then, that most students are unable to use the inexhaustible capacities that EFL dictionaries hold ready for them.

It was only fairly recently that dictionary use was undertaken from the perspective of the learner. This was initiated by Tomaszczyk (1979) and, more significantly, Bejoint (1981) whose questionnaire-based methodology influenced later researchers (and the current paper) such as Battenburg (1991), Stein (2002, 2004), Atkinson (1998) and Hartmann (2005). Certain tendencies in dictionary use among EFL students first noted by Bejoint and confirmed by other researchers include the correlation of bilingual and monolingual dictionary use with language proficiency; the dominance of decoding activities in dictionary utilization such as reading over encoding ones including writing; the relative ignorance about dictionary front-matter and appendices and the discrepancy between students' belief in the importance of dictionaries (particularly monolingual ones) and their apparent inability to exploit them on account of lack of knowledge and proper lexicographical skills. More importantly, all the previous studies point out that dictionaries are chiefly used as receptacles of meanings and equivalents, and that other information such as grammar, spelling, pronunciation and etymology are used much less, though in varying degrees.

Within Sudan, there have been two studies on dictionary competence, namely Ahmed (1994) and Abdullah (1996). While the latter is generally satisfied with students' dictionary awareness, the former is more skeptical about this awareness and its findings resemble those discussed above. Both ways, these two studies are limited in scope and investigate undifferentiated General English levels. In comparison, the present study explores the use of the resources of (monolingual) English dictionaries by a large sample of English majors in four Sudanese universities. 
Areas of interest include students' underlying motives and beliefs about dictionaries, the consulted aspects in dictionary entries and for what language activities, and the degree of mastery in executing these tasks and, indeed, their awareness of the rich information their (monolingual) dictionaries contain.

\subsection{Research Questions}

This study attempts to investigate Sudanese EFL learners' dictionary knowledge and practice; it is specifically designed to provide answers for the following questions:

1- What are the predominant notions associated with pedagogical dictionaries among this population sample?

2- How far do the samples utilize their pedagogical dictionaries for general, receptive and productive academic tasks?

3- Of the numerous entry components, which ones are the most and least looked up by the sample population, and how can this be explained?

4- What types of common difficulties do these students encounter while using their dictionaries?

\subsection{Significance of the Research}

The significance of this research stems from the fact that little is said about the use of dictionary by Sudanese learners. This study is an attempt to account for this essential learning tool. Hence, in the research we mainly target the Sudanese English Language learners. The result will be of great value to teachers and textbook designers. In addition, it will provide lexicographers with data to use in future work. While building on Bejoint's (1981) pioneering study, the present research deals with the self- same aspects and adds some dimensions replicated from such later studies as those by Hartmann (2005) and Stein (2002).This research is targeting teachers, students, researchers, syllabus designers and above all lexicographers.

\section{Methodology of the Study}

The subjects of the study are described and so is the allocation of sample size as well as data collection instrument and procedures.

\subsection{The Questionnaire}

This questionnaire inquires into students' beliefs, views, study habits and knowledge concerning components of English learners' dictionaries. This 30-item questionnaire is an adaptation of Bejoints' (1981) famous study of French students' familiarity with English dictionaries, whose replication by numerous other researchers implies a high degree of reliability. This study also includes modifications from Battenburg's (1992) study of dictionary habits of EFI students in American colleges, as well as aspects taken from Hartmann's (2005) more recent survey of dictionary use at Exeter University. The questionnaire is divided into six parts. Part (A) includes seven statements surveying students' beliefs about the merits and value of dictionaries as a language learning tool. Part (B) comprises seven statements concerning students' evaluation of the dictionaries available. Part (C) includes six statements analyzing students' preference for particular dictionary types as indicated by their purchase habits. Part (D) makes up six statements and analyses students' knowledge about secondary aspects in a dictionary such as front matter and appendices. Part (E), which includes one lengthy statement, considers students' knowledge and use habits concerning the main dictionary entry. Part (F) concerns students' frequency of use of dictionaries for language skills and other activities. The aim of this tool is to work out respondents' attitudes, evaluation, and actual use of dictionary for the sample population. A five Likert options scale is set to give a wide space of freedom for the subjects to easily respond to the options. The responses vary from strongly agree to strongly disagree. The responses to the questionnaire are at times further investigated through informal interviews with the students on specific points, and, indeed, these insights illuminate the whole discussion.

\subsection{Subjects of the Study}

The subjects of this study were taken from English majors studying in four Sudanese universities, namely University of Khartoum, Al Neelein University, Sudan University of Science and Technology, and Omdurman Islamic University during the academic year 2012- 2013. In the former two, the subjects were selected from colleges of Arts and in the latter from the colleges of Education. Following the stratified random sampling method to the total candidate population of the English Departments in the four universities as provided by the registrars of the respective institutions; 160 students were specifically chosen out of the total population of 1496. As the primary criterion of selection was specialization in English, the chosen population almost wholly belonged to the second year onwards. 
Hence, excluding the first year where English might be a general university subject not requiring the intensive use of dictionaries characteristic of English majors and which constitutes the rationale of the study. Thereupon, 160 questionnaires were given to students to fill in. This large proportion can be justified by the relative ease in filling out questionnaires and also by the fact that questionnaire method can probe the general tendencies among the population.

All subjects have received an average of 8-10 years of formal education in English as a foreign language, and they were educated under the same curriculum adopted in Sudan, i.e. SPINE, before they were enrolled in university. All subjects speak Arabic as a mother or second language. To conclude, the selected sample is homogeneous in educational level, linguistic background and span of pre-university instruction in the English language.

\subsection{Procedures}

An initial pilot study was carried out on ten students from The Department of English Faculty of Arts, University of Khartoum and resulting in minor modifications to ease the terminology and to provide illustrative examples. Subsequently, each group of students answering one test in one university was given the final instrument in a separate session. In the beginning they were given clear instructions and with an example showing how to fill in the questionnaire. A short text was attached to each copy to explain the objectives, and a brief oral presentation was provided to each group on the subject of dictionaries and their major taxonomies as well as the components of an entry in a monolingual English dictionary. The administration of students' questionnaire went smoothly in all four universities, with 160 copies completed. The researchers acted as the main examiners with another teacher from the concerned university as an assistant.

\section{Discussion}

This questionnaire is intended to measure the students' intensity of response to the various aspects of the theory and practice of the aspects of dictionaries. The subdivisions of the questionnaire will be dealt with in turn. Below are the tables containing percentages of students' scores. Simple percentage is used to reflect the responses of the testees.

\section{1 Underlying Beliefs about Dictionaries}

Table (1): Survey of Underlying Beliefs about Dictionaries

\begin{tabular}{|c|c|c|c|c|c|c|c|}
\hline Statement & & $\begin{array}{l}\text { I } \\
\text { strongly } \\
\text { agree }\end{array}$ & $\begin{array}{l}\text { I } \\
\text { agree }\end{array}$ & $\begin{array}{l}\text { I am } \\
\text { not } \\
\text { sure }\end{array}$ & I & $\begin{array}{l}\text { I } \\
\text { strongly } \\
\text { disagree }\end{array}$ & Total \\
\hline \multirow{2}{*}{$\begin{array}{l}\text { 1. Dictionrie are important to } \\
\text { language learning. }\end{array}$} & Count & 90 & 42 & 6 & 17 & 5 & 160 \\
\hline & $\%$ & $56 \%$ & $26 \%$ & $4 \%$ & $11 \%$ & $3 \%$ & $100 \%$ \\
\hline \multirow{2}{*}{$\begin{array}{l}\text { 2. A university student can master } \\
\text { English without having a } \\
\text { dictionary. }\end{array}$} & Count & 8 & 11 & 19 & 92 & 30 & 160 \\
\hline & $\%$ & $5 \%$ & $6 \%$ & $12 \%$ & $58 \%$ & $19 \%$ & $100 \%$ \\
\hline \multirow{2}{*}{$\begin{array}{l}\text { 3. Using a dictionary should be a } \\
\text { daily exercise to all Sudanese } \\
\text { learners of English. }\end{array}$} & Count & 66 & 49 & 16 & 21 & 8 & 160 \\
\hline & $\%$ & $41 \%$ & $31 \%$ & $10 \%$ & $14 \%$ & $5 \%$ & $100 \%$ \\
\hline \multirow{2}{*}{$\begin{array}{l}\text { 4. Dictionaries are preferable to } \\
\text { vocabulary guessing methods. }\end{array}$} & Count & 60 & 43 & 14 & 28 & 15 & 160 \\
\hline & $\%$ & $38 \%$ & $27 \%$ & $8 \%$ & $18 \%$ & $9 \%$ & $100 \%$ \\
\hline \multirow{2}{*}{$\begin{array}{l}\text { 5. It is better to have as many } \\
\text { dictionaries as possible. }\end{array}$} & Count & 14 & 10 & 24 & 87 & 25 & 160 \\
\hline & $\%$ & $9 \%$ & $6 \%$ & $15 \%$ & $54 \%$ & $16 \%$ & $100 \%$ \\
\hline \multirow{2}{*}{$\begin{array}{l}\text { 6. Using dictionaries is an } \\
\text { enjoyable and useful practice. }\end{array}$} & Count & 21 & 56 & 39 & 20 & 24 & 160 \\
\hline & $\%$ & $13 \%$ & $35 \%$ & $24 \%$ & $13 \%$ & $15 \%$ & $100 \%$ \\
\hline \multirow[t]{2}{*}{$\begin{array}{l}\text { 7. It is difficult to know how to use } \\
\text { a dictionary fully. }\end{array}$} & Count & 19 & 11 & 29 & 33 & 68 & 160 \\
\hline & $\%$ & $11 \%$ & $7 \%$ & $18 \%$ & $21 \%$ & $43 \%$ & $100 \%$ \\
\hline
\end{tabular}


Statement (1) concerns the importance of dictionaries in (English) language learning. The responses are clearly enthusiastic because $132(82 \%)$ as either "strongly agree" or "agree" - to that proposition as to leave no doubt about the naturalness of using dictionaries in the learning process. We can infer that in any serious English language programme owning a dictionary is axiomatic. Furthermore, our sample holds dictionaries in high esteem and, indeed, some of the students we interviewed mentioned that "the dictionary" is the unmistakable sign of learning a language. One student established this point further by explaining that exceptionally gifted students in English are referred to as dictionaries, thereby equating their competence in English in all language aspects with the ultimate embodiment of these components - the dictionary.

Statement (2) rephrases statement (1) by inquiring into the feasibility of mastering a language without resorting to a dictionary. This time $122(77 \%)$ out of the total of 160 students disagree with this other side of the coin. In our informed supplementary interviews with students many gave opinions to the effect that dictionaries are essential language complements. Compared with the teachers' limited lexicon, dictionaries are vast reservoirs for language learning that can be tapped at the students' will. It is true that teachers are active agents and dictionaries are passive, but it is a passivity of a rich kind for intentional and, more importantly, incidental learning of all aspects of the language.

As for statement (3), (daily dictionary use), 115 (70\%) of the students in principle concur with the view stressing the daily need of using dictionaries. This is not necessarily to be taken as literal but only as an indicator of the students' commitment, pointing to a high awareness of the importance of dictionaries among this representative sample. To measure this point further, the researchers selected 100 students and asked them about the frequency of their dictionary use. Only subjects 4 admitted to daily practice and 40 to once or twice a week. This falls short of percentages in Bejoint's (1981) classic study where $40 \%$ of his 122 French students used the dictionary at least once a day and 52\% at least once a week. However, the important point for our Sudanese sample is the fact that they felt they were not using dictionaries as much as they would. Naturally, there is the question of whether that use is of the effective kind. This point is answered in questions (29) and (30) of the questionnaire.

If dictionaries are so vital, it follows that students will prefer them to contextual guessing techniques, as indicated by question (4): (103 or 65\%) of the students do. Pedagogically speaking, the ability to use contextual cues comes only behind the dictionary as a source of vocabulary acquisition (Scholfield, 2002). But each method has its advantages. Hence, during the reading process dictionary use competes with various kinds of guessing. There is, according to Scholfied (ibid), strong evidence that expert reader make good choices about when each of them does not use the dictionary exclusively, and often about when they do so after making attempts at guessing. Amateur learners, on the other hand, tend to overuse dictionaries for comprehension purposes, particularly by looking up words unnecessarily (Nesi, 1999), which seems to be the case for our Sudanese students. If we think of our sample's standards of English declining sharply, it is understandable why they would gladly give up the pleasure of equivocation and self-independence in learning for the firmer ground of using the dictionary to exactly pinpoint meanings of words.

Students' answers to statement (5) (ownership of multiple dictionaries) comes as a surprise to us: 112 (70\%) were against the commonsensical view of the merits of owning as many dictionaries as possible. Again, this can be explained with reference to the students' weak linguistic competence and so the possession of many dictionaries may be deemed confusing. Then, each dictionary will have its unique features, but students may not be able to digest these assorted ingredients. Statement (6) (pleasure and usefulness of dictionaries) has seemingly proved difficult for students, as dictionaries can be pleasurable without being useful and vice versa. To resolve this, we instructed our students to register their responses to either one of them. Most of the 77 (48\%) students with positive responses stress the usefulness of dictionaries rather than their joy. Thus, dictionaries are indispensable sources to be used out of necessity rather than pleasure. It can be said that for students, and people at large, it is difficult to associate dictionaries with pleasure. The place and value of this necessary, though unpalatable, source is thus confirmed by the previous six statements. Question (7) is one of the degrees of the difficulty of using it. The students, rather surprisingly, believe dictionaries to be easily manageable transparent sources. Roughly 101 (74\%) have this facile view which goes against the perceptions of lexicographers worldwide (e.g. Atkins, 1998).

We can generalize that students' attitudes towards the dictionary are on the whole positive, albeit a little overconfident. The preponderance of positive answers may suggest an exaggerated feeling of self-satisfaction (much the same conclusion is reached by Abdullah (1996), Bejoint (1981) and Hartmann (2005). 
For our Sudanese sample, this optimism in turn needs to be balanced against such overlapping issues as ignoring other people's advice on buying dictionaries (question 18), managing without guidance (questions 21 and 27), and ascribing search problems wholly to dictionary design (question 30). However students' optimism and enlightened views persist and they are the more surprising in the face of teachers' responses and within an academic atmosphere where lexicography is given only little attention (Ali and Siddiek, 2014).

\subsection{Evaluation of Different Types of Dictionary}

Table (2): Survey of Students' Evaluation of Different Types of Dictionaries

\begin{tabular}{|c|c|c|c|c|c|c|c|}
\hline Statement & & $\begin{array}{l}\text { I } \\
\text { strongly } \\
\text { agree }\end{array}$ & $\begin{array}{l}\text { I } \\
\text { agree }\end{array}$ & $\begin{array}{l}\text { I am } \\
\text { not } \\
\text { sure }\end{array}$ & $\begin{array}{l}\text { I } \\
\text { disagree }\end{array}$ & $\begin{array}{l}\text { I } \\
\text { strongly } \\
\text { disagree }\end{array}$ & Total \\
\hline \multirow{2}{*}{$\begin{array}{l}\text { 8. Monolingual are better than bilingual } \\
\text { dictionaries. }\end{array}$} & Count & 86 & 37 & 12 & 16 & 9 & 160 \\
\hline & $\%$ & $54 \%$ & $23 \%$ & $8 \%$ & $10 \%$ & $5 \%$ & $100 \%$ \\
\hline \multirow{2}{*}{$\begin{array}{l}\text { 9. In some respects, bilingual are better } \\
\text { than monolingual dictionaries. }\end{array}$} & Count & 6 & 16 & 27 & 61 & 50 & 160 \\
\hline & $\%$ & $4 \%$ & $10 \%$ & $17 \%$ & $38 \%$ & $31 \%$ & $100 \%$ \\
\hline \multirow{2}{*}{$\begin{array}{l}\text { 10. It would be best to combine } \\
\text { monolingual and bilingual dictionaries } \\
\text { into bilingualised dictionaries (English- } \\
\text { Arabic- English). }\end{array}$} & Count & 10 & 13 & 70 & 44 & 23 & 160 \\
\hline & $\%$ & $6 \%$ & $8 \%$ & $44 \%$ & $28 \%$ & $14 \%$ & $100 \%$ \\
\hline \multirow{2}{*}{$\begin{array}{l}\text { 11. Electronic dictionaries have some } \\
\text { advantages over paper-based ones. }\end{array}$} & Count & 21 & 64 & 26 & 30 & 19 & 160 \\
\hline & Count & $13 \%$ & $40 \%$ & $17 \%$ & $18 \%$ & $12 \%$ & $100 \%$ \\
\hline \multirow{2}{*}{$\begin{array}{l}\text { 12. Electronic dictionaries are more } \\
\text { limited in some aspects than paper-based } \\
\text { ones. }\end{array}$} & $\%$ & 46 & 32 & 19 & 28 & 35 & 160 \\
\hline & Count & $29 \%$ & $20 \%$ & $12 \%$ & $17 \%$ & $22 \%$ & $100 \%$ \\
\hline \multirow{2}{*}{$\begin{array}{l}\text { 13. Sudanese students at the university } \\
\text { levels should use advanced dictionaries } \\
\text { (e.g. Oxford Advanced Learners' } \\
\text { Dictionary). }\end{array}$} & $\%$ & 51 & 47 & 9 & 30 & 23 & 160 \\
\hline & Count & $32 \%$ & $29 \%$ & $6 \%$ & $19 \%$ & $14 \%$ & $100 \%$ \\
\hline
\end{tabular}

We will now move on to students' opinions of the taxonomy of dictionaries. The most easily observable of these distinctions is, of course, the one between monolingual and bilingual dictionaries (Atkins, 1985). Our subjects are almost wholly unanimous in their praise of monolinguals with $123(77 \%)$ holding them in high esteem. With the students' low levels of English in the post -Arabicisation era (Braima, 2004), the figures were expected to be lower. Originally, Sudan was a British colony with the resultant dominance of English in such institutions as Gordon Memorial College established in 1902 and later renamed The University of Khartoum, Sudan's oldest and most prestigious university, where, again, English was never challenged as a medium of instruction. The hegemony of English extended to higher secondary schools where up to the 1960s almost all subjects were taught in English (Sandell, 1982; Al Busairi, 2002)). That situation was profoundly shaken with the coming of mass Arabicisation and Islamization of knowledge in the 1990s up to the present. Presumably, because of this strong Anglophone heritage, monolingual dictionaries are still thought of as the best, and bilingual dictionaries are much less easily accepted as it would be the case in countries like Syria and Iraq with strong tradition of Arabic nationalism in politics and education. The above analysis is confirmed by statement (9) on bilingual dictionaries. Strangely enough, $111(69 \%)$ of our sample rejects them, testifying to the belief cherishing the value of monolinguals in Sudan. In face of the relative ease and acceptability of bilingual dictionaries for weaker students (Scholfied, 1982), figures are astounding. However, this should by no means be taken as indicating that students' use of bilinguals reflects their beliefs. This is partly reflected in statement (13) where only a slight majority of 98 (61\%) view advanced monolingual dictionaries should be the first choice for students.

Equally, students disregard bilingualised dictionaries, which is a recent phenomenon (statement 10). A significant proportion of $70(44 \%)$ are not even aware of their existence, while $67(42 \%)$ dismiss them as being of little use. Some of the students we have interviewed mentioned that the mere name of Arabic in a dictionary indicates it is less than good and is yet one more version of a bilingual dictionary. 
However, it was interesting for the researchers to note the disjunction between students' rejection of a concept and their actual practices, as a sizeable number of students were observable using The Oxford English- ArabicEnglish Dictionary and it would not be an exaggeration to suggest that bilingualized dictionaries are a popular choice in the Sudanese market.

Table (3): Survey of Students' Rating of Dictionaries

\begin{tabular}{|l|l|l|l|l|l|l|l|}
\hline $\begin{array}{l}\text { 14. How do you rate the following } \\
\text { dictionaries? }\end{array}$ & & Excellent & $\begin{array}{l}\text { Very } \\
\text { good }\end{array}$ & Good & $\begin{array}{l}\text { Not } \\
\text { sure }\end{array}$ & Unsatisfactory & Total \\
\hline $\begin{array}{l}\text { A .Monolingual (e..g. Oxford Advanced } \\
\text { Learners' Dictionary, Longman } \\
\text { Dictionary of, Contemporary English) }\end{array}$ & Count & 90 & 22 & 33 & 15 & 0 & 160 \\
\cline { 2 - 8 } & $\%$ & $56 \%$ & $14 \%$ & $21 \%$ & $9 \%$ & $0 \%$ & $\begin{array}{l}\% \\
100\end{array}$ \\
\hline $\begin{array}{l}\text { b.Bilingual ( e.g Muneer Al Baalabaki } \\
\text { English - Arabic Dictionary) }\end{array}$ & Count & 9 & 24 & 36 & 15 & 76 & 160 \\
\cline { 2 - 8 } $\begin{array}{l}\text { c.Bilingualized (e.g Oxford English- } \\
\text { Arabic-English Dictionary). }\end{array}$ & Count & 41 & 27 & 24 & 19 & 49 & 100 \\
\hline & $\%$ & $25 \%$ & $17 \%$ & $15 \%$ & $12 \%$ & $31 \%$ & $100 \%$ \\
\hline d..Electronic dictionaries. & Count & 7 & 14 & 32 & 11 & 96 & 160 \\
\cline { 2 - 8 } & $\%$ & $4 \%$ & $9 \%$ & $20 \%$ & $7 \%$ & $60 \%$ & $100 \%$ \\
\hline $\begin{array}{l}\text { e..Thesauruses (e.g The Cambridge } \\
\text { Dictionary of Collocations). }\end{array}$ & Count & 3 & 5 & 4 & 109 & 39 & 160 \\
\cline { 2 - 7 } & $\%$ & $2 \%$ & $3 \%$ & $3 \%$ & $68 \%$ & $24 \%$ & $100 \%$ \\
\hline
\end{tabular}

A more recent and recognizable form of dictionaries are the electronic dictionaries. It was explained to students that such choice includes both explicit dictionaries and language enhancements on smart i-phones (statement II). Despites questions about their affordability to students in public universities in a developing Country, 85 (53\%) of the students see advantages in them, a fact. Our Sudanese students mentioned advantages of such dictionaries as similar to those enumerated by Nakamura (2003), namely accessibility, portability and ease of reference. Nonetheless, this positive noted has to be contrasted with statement (12) indicating that 78 (49\%) of the students believe electronic dictionaries to be more limited in some aspects than their paper-based Counterparts, probably on account of their superficiality, low retention levels, focus on isolated words and their essentially bilingual nature. Regarding rating of dictionary types, they are covered by statement (14). In fact, table (3) above offers another re-ordering of the above arguments, as it explicitly asks about the ranking of different dictionaries. As expected, $90(56 \%)$ hold monolinguals to be excellent, $22(14 \%)$ as very good and no student believes them as bad. This stands in contrast with the students' views about bilinguals with only $9(5 \%)$ holding them to be excellent and 76 (48\%) believing them to be overtly detrimental.

As for bilingualised dictionaries, students were almost equally divided in their rating of them, with $42 \%$ for and $43 \%$ against. The researchers, however, believe that bilingualised dictionaries have not received the attention they deserve since they absorb the benefits of both worlds (Raudaskoski, 2002). Continuing with the categories, it is understandable that in an impoverished Country electronic dictionaries are not rated highly, with only 7 students holding them to be "excellent", 14 to be "very good" and, on the other hand, 96 to be "bad". Explanations have to be offered for this, and in our interviews some students complained of the superficiality of these and their elementary nature unbefitting university English majors, as well as their high prices that are beyond the reach of many students in this sample of largely governmental universities.

Recent additions to the arsenal of dictionaries are the thesauruses (a development largely due to contemporary lexical theories of language on such areas as vocabulary dimensions, idioms and phraseology. However, these insights have apparently not found their way into Sudanese students' classrooms still dominated by syntax and morphology (Abdullah, 2005). It is no wonder that, most students have not heard of this specialized dictionary which explains the high incidence of $109(68 \%)$ of "unsure" for question. 14 (e), while a significant proportion of 39 (24\%) hold them to be good, primarily due to their monolingual nature. A subcategory is the relative ranking of use of dictionary types. Only $59(37 \%)$ have chosen monolingual dictionaries as their first actual choice, only slight higher than bilinguals $48(29 \%)$ contrasted with $33(21 \%)$ for electronic dictionaries, 20 (13\%) for bilingualized and none for thesauruses. A very important finding emerges, namely that students do not use monolinguals as much as they would. The researchers propose to call this The Paul Effect on a par with The Matthew Effect in bibliometrics (Howard, 2008) to account for the concentration of citations in few sources. 
According to St. Paul (Roman, 7:15) I do not understand what I do. For I want to do I do not do, but what I hate I do. This might be similar to the conception of monolingual dictionaries as desired choice requiring a great effort and, hence, the temptation of bilingual and electronic dictionaries. Returning to our Sudanese sample, the important sections for us are the users of monolingual dictionaries as their first actual choices. These are not necessarily users of such classic dictionaries as OALD or LDOCE, but more probably of the accessible student friendly dictionaries like Michael West New Method Dictionary or Longman Active Study Dictionary.

\subsection{Dictionary Purchase Motivations}

This relatively short section looks into the motivation behind the students' buying some dictionaries rather than others. It seems that the buying process is largely chaotic, that most students buy on the spur of the moment. This is clear from statement 15 (relevance to need), where "sometimes" accounts for "21\%" of the cases, "rarely" for "34\%" and "never" for 20\%. Consequently, there is little correlation between perceived needs and buying incidents. Some of the students we interviewed mentioned they are merely motivated by the sight of a dictionary owned by a colleague on finding it useful or attractive. Also, other students expressed a desire to own a dictionary with a glamorous name like "Oxford" or "Longman". Hence, it can be concluded that the above factors have a little to do with pedagogical relevance.

Table (4) Students' Dictionary Purchase Habits

\begin{tabular}{|c|c|c|c|c|c|c|c|}
\hline Statement & & Always & Often & Sometimes & Rarely & Never & Total \\
\hline \multirow{2}{*}{$\begin{array}{l}15 . \text { I buy the dictionary that is only } \\
\text { relevant to my needs. }\end{array}$} & Count & 17 & 22 & 35 & 54 & 32 & 160 \\
\hline & $\%$ & $12 \%$ & $13 \%$ & $21 \%$ & $34 \%$ & $20 \%$ & $100 \%$ \\
\hline \multirow{2}{*}{$\begin{array}{l}\text { 16. The number of entries is important when I } \\
\text { buy dictionaries. }\end{array}$} & Count & 20 & 44 & 33 & 35 & 28 & 160 \\
\hline & $\%$ & $12 \%$ & $28 \%$ & $21 \%$ & $22 \%$ & $17 \%$ & $100 \%$ \\
\hline \multirow[t]{2}{*}{ 17..I buy dictionaries for particular occasions. } & Count & 7 & 12 & 19 & 58 & 64 & 160 \\
\hline & $\%$ & $4 \%$ & $8 \%$ & $12 \%$ & $36 \%$ & $40 \%$ & $100 \%$ \\
\hline \multirow{2}{*}{$\begin{array}{l}\text { 18.I consult my teachers when buying a } \\
\text { dictionary. }\end{array}$} & Count & 5 & 13 & 10 & 56 & 76 & 160 \\
\hline & $\%$ & $3 \%$ & $8 \%$ & $6 \%$ & $35 \%$ & $48 \%$ & $100 \%$ \\
\hline \multirow[t]{2}{*}{ 19.I choose only dictionaries that I can afford. } & Count & 70 & 33 & 26 & 19 & 12 & 160 \\
\hline & $\%$ & $44 \%$ & $21 \%$ & $16 \%$ & $11 \%$. & $8 \%$ & $100 \%$ \\
\hline \multirow{2}{*}{$\begin{array}{l}20 . I \text { think that money spent on dictionary is } \\
\text { money lost. }\end{array}$} & Count & 6 & 15 & 19 & 64 & 56 & 160 \\
\hline & $\%$ & $4 \%$ & $9 \%$ & $12 \%$ & $40 \%$ & $35 \%$ & $100 \%$ \\
\hline
\end{tabular}

It appears from Table (4) above that size considerations (statement 16) are important: "Always" and "often" account for $40 \%$ and "sometimes" for $21 \%$. We can then infer that for these students, dictionaries are like a commodity: the bigger, the better, and more assuring in that students expect they will have more return for their money. Curiously enough, these students are unaware of how accurate their measure is, as "size" is important for lexicographers too, because it is translated in terms of entries, and a larger size indicates more inclusiveness.

There is no signal of how random the buying process than statement 17 (buying on occasions), where only seven students choose "always" 11 "often", while "never" covers 64 (40\%) of students. As one might have expected, occasions such as the beginning of the academic year or translation examinations did not appear to be major triggers of dictionary purchase. Concerning involving teachers in the buying process, a vast majority (83\%) hardly do so, possibly due to a misguided self- confidence that is accentuated by the aforementioned antipathy on the part of teachers. While two- thirds of students are financially conscious when purchasing dictionaries (statement $19)$, it does not follow that a majority $(75 \%)$ of these students will go to great lengths to procure this tool, evidenced by statistics of statement (20).

\subsection{Occasions of Dictionary Consultation}

Dictionary consultation can be spontaneous, as when the dictionary itself becomes an object of pleasure and contemplation in its various structures However, it is more normal for dictionary use to be timed with different occasions. The first of these is, naturally, the classroom (statement 20 (a)), Table (5), such as when students look up a word mentioned by their teacher or a word encountered in an in-class reading assignment. On such occasions, students keep the dictionary by their activity in case of an emergency. In our questionnaire this occurs little -13 (8\%) "always", 17 (11\%) "often" and 31 (19\%) "sometimes". One would have expected students to be employing dictionaries more in those normal and frequent cases of need. 
One explanation can be sought in the teachers' apathy, as teachers hold back the encouragement needed by students for the latter to use their dictionaries during class. This point is verified by a separate study (Ali and Siddiek, 2014) on Sudanese English teachers' dictionary perceptions and practices, in which $98 \%$ of teachers do not encourage their students to employ dictionaries during class. Indeed, only slightly over half of the surveyed teachers attempt to inoculate in their students the notion that dictionaries are indispensible learning tools.

Table (5): Survey of Occasions for Dictionary Use

\begin{tabular}{|l|l|l|l|l|l|l|l|}
\hline $\begin{array}{l}\text { 21. How often do you use your dictionary } \\
\text { for the following activities? }\end{array}$ & Always & Often & Sometimes & Rarely & Never & Total \\
\hline \multirow{2}{*}{ a. During class. } & Count & 13 & 17 & 31 & 58 & 41 & 160 \\
\cline { 2 - 8 } & $\%$ & $8 \%$ & $11 \%$ & $19 \%$ & $36 \%$ & $26 \%$ & $100 \%$ \\
\hline \multirow{2}{*}{ b. During reading. } & Count & 53 & 38 & 42 & 20 & 7 & 160 \\
\cline { 2 - 8 } & $\%$ & $33 \%$ & $24 \%$ & $26 \%$ & $13 \%$ & $4 \%$ & $100 \%$ \\
\hline \multirow{2}{*}{ c. During leisure activities. } & Count & 5 & 14 & 21 & 66 & 54 & 160 \\
\cline { 2 - 8 } & $\%$ & $3 \%$ & $9 \%$ & $13 \%$ & $41 \%$ & $34 \%$ & $100 \%$ \\
\hline \multirow{2}{*}{ d. During speaking. } & Count & 15 & 14 & 31 & 54 & 46 & 160 \\
\hline & $\%$ & $9 \%$ & $9 \%$ & $19 \%$ & $34 \%$ & $29 \%$ & $100 \%$ \\
\hline \multirow{2}{*}{ e.During writing. } & Count & 0 & 1 & 3 & 5 & 151 & 160 \\
\cline { 2 - 8 } & $\%$ & 0 & $0.6 \%$ & $2 \%$ & $3 \%$ & $94.4 \%$ & $100 \%$ \\
\hline f. During listening. & Count & 2 & 4 & 10 & 7 & 137 & 160 \\
\hline & $\%$ & $1 \%$ & $3 \% 3$ & $6 \%$ & $4 \%$ & $86 \%$ & $100 \%$ \\
\hline
\end{tabular}

If the classroom is a collective activity presided over by the teacher, an investigation is worthwhile into students' individual employment of dictionary shown in the four traditional language skills of reading, writing, listening and speaking. Though these distinctions could be found unsatisfactory in language teaching), they could be used here as a starting point. For foreign students, translation must be added, both translation from $\mathrm{L}_{1}$ to. $\mathrm{L}_{2}$ (Arabic into English), and in our case $\mathrm{L}_{2}$ to. $\mathrm{L}_{1}$ ( English into Arabic). The above activities can be grouped into two categories, according to Bejoint (1981: 209) - reading and listening which involve, above all, the comprehension of $\mathrm{L}_{2}$ text and can be called "decoding activates"; writing and speaking are, in contrast, "encoding activities". The basic decoding activity is reading and the scores are significant -53 (32\%) is "always", 38 (24\%) "often". Reading here is taken in the passive sense of a chiefly academic matter. Another type of reading is done outside the classroom in the form of leisure activities such as reading the Newsweek, classic literature like Dickens, thrillers like Agatha Christie, or simply browsing through the internet for sheer pleasure. It turns out that these poststructural students enamoured with superficiality and visual images at the expense of printed words ( Lyotard, 1997) and the use of dictionaries they entail: 5 students choose "always, 14 "often", 66 "rarely" and 54 "never".

If academic reading scores well, writing, another major trigger of dictionary use, scores less for this sample: 15 (9\%) "always", and 14 (8\%) "often". The figures compare unfavorably with Bejoint's (1981) study, where reading has an $86 \%$ in relation to $60 \%$ for writing. Equally, unlike Stein (2002), Tomaszczy (1979), and Benousson and Weiss (1983). our sample used the dictionary more for reading than for writing. The figures drop even further for speaking in our sample. Understandably, only 6 students use dictionaries for speaking on a regular basis, while a large proportion of $137(85 \%)$ never do.

The figures are much less than Bejoint's average of $14 \%$. As for using dictionaries during listening, the statistics are zero for "always" and one student is for "often", while $94 \%$ for "never". Again, this is understandable, as it is virtually impossible to use the dictionary simultaneously with listening, as sound is transient and flows uninterruptedly.A related, but separate, activity is the use of the dictionary during (pedagogical) translation courses offered in the four universities and for which use of the dictionary is thought to be necessary. Taking into consideration the fact that translation examinations allow for the use of dictionaries, except electronic ones, believed, to ease, the task beyond acceptable limits, the figures are correspondingly high - 111 (69\%) go for "always", while no scores go for "never". In Sudanese universities the safer course is taken: with the exception of translation dictionaries are not allowed in examinations because they are believed to interfere with academic integrity. However, as matters stand at present with the prohibition of dictionaries during examinations, the bulk of students 136 (85\%) "never" use them, and only 9 "often", with the exception of translation where they do so keeping away from invigilators' eyes. 


\subsection{Students' Knowledge of Dictionary Secondary Matter}

\section{Table (6): Survey of Students' Knowledge of Dictionary Secondary Matter}

By "secondary matter" we mean those aspects of the dictionary related to the macrostructure, the peripheral parts

\begin{tabular}{|l|l|l|l|l|l|l|l|}
\hline Statement & & Always & Often & Sometimes & Rarely & Never & Total \\
\hline \multirow{2}{2}{$\begin{array}{l}\text { 21.I start using the dictionary without looking } \\
\text { at the introduction.. }\end{array}$} & Count & 57 & 49 & 25 & 18 & 11 & 160 \\
\cline { 2 - 8 } & $\%$ & $35 \%$ & $31 \%$ & $16 \%$ & $11 \%$ & $7 \%$ & $100 \%$ \\
\hline 22.I know the title of my dictionary.. & Count & 81 & 39 & 13 & 10 & 17 & 160 \\
\cline { 2 - 8 } & $\%$ & $51 \%$ & $24 \%$ & $8 \%$ & $6 \%$ & $11 \%$ & $100 \%$ \\
\hline $\begin{array}{l}\text { 23.I know the publisher and the publication } \\
\text { date of my dictionary. }\end{array}$ & Count & 8 & 22 & 29 & 45 & 56 & 160 \\
\cline { 2 - 8 } & $\%$ & $5 \%$ & $14 \%$ & $18 \%$ & $28 \%$ & $35 \%$ & $100 \%$ \\
\hline $\begin{array}{l}\text { 24.I carefully study the appendices of my } \\
\text { dictionary. }\end{array}$ & Count & 12 & 10 & 23 & 60 & 55 & 160 \\
\hline & $\%$ & $8 \%$ & $6 \%$ & $14 \%$ & $38 \%$ & $34 \%$ & $100 \%$ \\
\hline $\begin{array}{l}\text { 25.I apply the phonetic transcription without } \\
\text { referring to the appendices. }\end{array}$ & Count & 3 & 9 & 16 & 51 & 81 & 160 \\
\hline & $\%$ & $2 \%$ & $6 \%$ & $10 \%$ & $31 \%$ & $51 \%$ & $100 \%$ \\
\hline $\begin{array}{l}\text { 26.I cam give the full form of most of the } \\
\text { abbreviation in my dictionary. }\end{array}$ & Count & 33 & 44 & 28 & 18 & 37 & 160 \\
\hline & $\%$ & $21 \%$ & $28 \%$ & $17 \%$ & $11 \%$ & $23 \%$ & $100 \%$ \\
\hline $\begin{array}{l}\text { 27.I make sure to study the defining } \\
\text { vocabulary in my dictionary. }\end{array}$ & Count & 11 & 36 & 53 & 30 & 30 & 160 \\
\hline & & & & & $19 \%$ & $19 \%$ & $100 \%$ \\
\hline
\end{tabular}

as opposed to the microstructure, the main parts of the dictionary. However, this does not mean that the former are less important than the latter, and in one sense one cannot approach one without the other (Ahmed, 1994). These components will be dealt with in turn. Statement (21) in Table (6) above investigates how students relate to the dictionary introduction designed to help students and given so much care by lexicographers. The introduction is almost invariably overlooked by students: 57 (35\%) "never" look at it, 49 (31\%) do so "rarely".. These figures are not far removed from international studies where Bejoint (1981), for example, mentions that $89 \%$ of his sample neglects the introduction and Hartmann (2005) in whose study $70 \%$ of the students claimed that they could manage without the introduction. All in all, it is believed that this neglect on the part of the students will create problems, as is clear from responses to the last part of this questionnaire. Statement (22) is more focused and concerns knowledge of the dictionary title. As expected, 81 (51\%) "always" do, 39 (24\%) "often"do. But on interviewing students, it came out that their knowledge of the title goes far but no further: they can only remember the household catchwords in the title like Oxford, Longman and Al Mawrid but not their gradation of levels designed to satisfy the needs of different sets of students including elementary, intermediate, and advanced levels. This is invaluable information that helps students in choosing the dictionary that fits their requirements.

An equally important piece of information is the publisher and publication date. While the publishers (and even editors) are rarely significant except for the "Oxford" brand and such famous editors as A.S. Hornby, the publication date is crucial, as dictionaries are being constantly updated to keep abreast with developments in the language. This entails producing new editions (that is, with emendations) every certain number of years (editions of OALD, for instance, appeared in 1948, 1963, 1974, 1989, 1995, 2000 , 2006 and 2010). Impressions, on the other hand, are mere imprints (with no amendments) and are produced when need arises in the readership market. Unfortunately, only $8(5 \%)$ students are constantly aware of this information and only $22(14 \%)$ are "often" so.

Prominent in the secondary matter are the appendices. In our present sample, only $12(8 \%)$ "always" look at them and $10(6 \%)$ "often" do so. Many students admit that their chief interest in the main pages of the appendices is restricted to tables of regular verbs (an obsession with our grammatically-minded Sudanese students). Awareness of appendices is however low in the other studies: 40\% in Bejoint's (1981) study and 30\% in Hartmann's (2005). As for phonetic keys statement (25), they are held to be important as they facilitate proper pronunciation of words (Roach, 1995), but only 12 students pay them any great attention, and this will negatively impact knowledge of pronunciation, as will become clear later. Surprisingly enough, the feature of abbreviations, normally included in the appendices, has a special appeal to our students who treat them as puzzles to be solved and can generate a great deal of fun. 


\begin{tabular}{|c|c|c|c|c|c|c|c|}
\hline Statement & & Always & Often & Sometimes & Rarely & Never & Total \\
\hline \multirow{2}{*}{ a. Definitions. } & Count & 98 & 36 & 17 & 8 & 1 & 160 \\
\hline & $\%$ & $61 \%$ & $23 \%$ & $10 \%$ & $5 \%$ & $1 \%$ & $100 \%$ \\
\hline \multirow[t]{2}{*}{ b. Arabic equivalents. } & Count & 77 & 40 & 21 & 18 & 4 & 160 \\
\hline & $\%$ & 48 & $25 \%$ & $13 \%$ & $11 \%$ & $3 \%$ & $100 \%$ \\
\hline \multirow[t]{2}{*}{ c. Illustrative examples. } & Count & 8 & 20 & 16 & 28 & 88 & 160 \\
\hline & $\%$ & $5 \%$ & $12 \%$ & $10 \%$ & $18 \%$ & $55 \%$ & $100 \%$ \\
\hline \multirow[t]{2}{*}{ d. Cross reference. } & Count & 3 & 10 & 17 & 49 & 81 & 160 \\
\hline & $\%$ & $2 \%$ & $6 \%$ & $11 \% \%$ & $31 \%$ & $50 \% \%$ & $100 \%$ \\
\hline \multirow[t]{2}{*}{ e. Pictorial illustrations. } & Count & 4 & 15 & 41 & 33 & 67 & 160 \\
\hline & $\%$ & $2 \%$ & $9 \%$ & $26 \%$ & $21 \%$ & $42 \%$ & $100 \%$ \\
\hline \multirow[t]{2}{*}{ f. Pronunciation. } & Count & 13 & 21 & 10 & 23 & 93 & 160 \\
\hline & $\%$ & $8 \%$ & $13 \%$ & $6 \%$ & $14 \%$ & $59 \%$ & $100 \%$ \\
\hline \multirow{2}{*}{ g. Part of speech. } & Count & 11 & 27 & 50 & 19 & 53 & 160 \\
\hline & $\%$ & $7 \%$ & $17 \%$ & $31 \%$ & $12 \%$ & $33 \%$ & $100 \%$ \\
\hline \multirow[t]{2}{*}{ h. Morphological information. } & Count & 9 & 18 & 61 & 40 & 32 & 160 \\
\hline & $\%$ & $6 \%$ & $11 \%$ & $38 \%$ & $25 \%$ & $20 \%$ & $100 \%$ \\
\hline \multirow[t]{2}{*}{ i. Syntactic patterns. } & Count & 9 & 21 & 28 & 33 & 69 & 160 \\
\hline & $\%$ & $6 \%$ & $13 \%$ & $17 \%$ & $21 \%$ & $43 \%$ & $100 \%$ \\
\hline \multirow[t]{2}{*}{ j. Spelling. } & Count & 36 & 16 & 28 & 54 & 26 & 160 \\
\hline & $\%$ & $22 \%$ & $10 \%$ & $18 \%$ & $34 \%$ & $16 \%$ & $100 \%$ \\
\hline \multirow[t]{2}{*}{ k. Collocations. } & Count & 43 & 10 & 13 & 60 & 34 & 160 \\
\hline & $\%$ & $27 \%$ & $6 \%$ & $8 \%$ & $38 \%$ & $21 \%$ & $100 \%$ \\
\hline \multirow[t]{2}{*}{ 1. Level of use. } & Count & 17 & 31 & 22 & 39 & 51 & 160 \\
\hline & $\%$ & $11 \%$ & $19 \%$ & $14 \%$ & $24 \%$ & $32 \%$ & $100 \%$ \\
\hline m. Varieties of English. & Count & $18(11 \%)$ & $26(16 \%)$ & $15(9 \%)$ & $54(34 \%)$ & $47(30 \%)$ & 160 \\
\hline
\end{tabular}

Figures prove this: 33 (21\%) "always", 44 (28\%) "often". These statistics run close to Bejoint's (1981) average of $40 \%$ of students and Hartmann's (2005),'(52\%). The implication of these figures is that they consolidate the impression of the dictionary as a decoding tool, its role above all being to elucidate meanings, linking to the function of definition (see 29 (a) of the questionnaire). Finally, most pedagogical dictionaries include defining vocabulary to help render the definitions clear by having students know in advance about words employed so as to study them beforehand. The fact is that 11(7\%) opt for "always", 36 (22\%) for "often", while 30 (19\%) only "rarely" look at them and 30, again, "never" do so, despite the fact pointed out by Stein (2002) that this feature is specifically meant to be used by every student.

The general impression is that hardly any of the above ancillary features are utilized fully by our students, which will have implications for proper dictionary use, as indicated by question (30). In one sense, inattention to secondary dictionary features by EFL students worldwide is well-attested in the literature (Landau, 1989); our Sudanese sample being no exception, while this is clear, what is to be done to resolve it is, unfortunately, a matter of debate.

\subsection{Students' Use of the Main Dictionary Entry}

An EFL dictionary is meant to serve two basic functions. Dictionary components are categorized into those of decoding and those of encoding. As for the former, the most important kind of information is, of course, the denotation of the lexeme and, to a lesser extent, connotative meaning, language variety and idioms (Bejoint, 1981: 210). Landau (1989) adds the information on irregular grammatical inflections, tense, number or comparison for their value in decoding as they help the user identify a lexeme for the various word forms which realize it. Regarding encoding, the students need to know the spelling and syllabification of items if they are writing and their pronunciation if they are speaking. For both modes, the dictionary must indicate the grammatical information, the language variety, the usual collocations and the syntactic properties of the treated items (Stein, 2002). 
However, for our present purpose, it is sufficient to limit ourselves to the canonical dictionary entry items mentioned in Atkins (1985), and which form the crux of this questionnaire (statement 30). Let us turn to the frequency of use for these components in detail.

It is only natural to start with the definitions, that is, the enumeration of the different senses of the lexeme. The place definitions have for lexicographers are epitomized by Kiefer (1994: 11) in his claim that definitions are the meat of lexicographical profession. No other component requires as much space and labor and affects the potential success or failure of the dictionary text. The question is one of whether our students attach to them the same attention they proved to have had in other studies worldwide. Responses in Table (7) above rebound with a strong "yes" 98 (61\%) choose "always", 36 (23\%) "often", and only one student decides on "never"- the percentage is close to that in Ahmed's (1994) where 63\% chose meanings as their first choice. In the two studies it appears that students treat the dictionary as a receptacle of meanings to be used in time of need, and basically as an inventory of words with glosses. This view is largely present in other studies. For instance, $87 \%$ of Bejoint's respondents placed meaning among the most sought-after pieces of information. Also, Hartmann's (2005) subjects showed a strong preference for looking up definitions and a parallel lack of interest in other items. Another version of definitions is the Arabic equivalents employed in bilingual and bilingualised dictionaries, where scores are equally high: 77 (48\%) "always", 40 (25\%) as "often". This runs Counter to the dissatisfaction students expressed with bilingual dictionaries in the early part of the questionnaire. The difference between theory and practice only points to the trap and paradoxical temptation these dictionaries set for the students.

Some components are related to definitions such as illustrative examples which are used to clarify the senses of the lexeme. Though being an integral part of a proper definition, illustrative examples are barely given attention when compared with their mother entry component: only 8 students look them up "always", 20 "often", in contrast to $88(55 \%)$ for "never", For mainstream lexicographers, it is no comfort to hear judgments from their recent corpus-influenced colleagues such as Sinclair (1995) who does not believe the above figures to be alarming since most illustrative examples are, in any case, too difficult, artificial or unhelpful to be of use.

Another definition -related feature, cross-reference, which sheds light on the word family of a lexeme, is hardly looked up at all: only 3 students go for "always", 10 for "often", while there are 81 (50\%) cases of "never". Though increasingly assigned a role in EFL dictionaries, cross-reference is seldom used, perhaps because of the alphabetical ordering of the dictionary where cross-referenced items are widely dispersed and hence not accessible (this is why many lexicographers have pointed out the importance of thematic dictionaries). In the same vein, elucidation of definitions increasingly relies on using pictorial illustrations (Hupka, 1995), but these are surprisingly little used by students: 4 "always", 15 "often", and 67 cases of "never". A plausible explanation is the educational background of our sample students who are not much used to this feature in their SPINE series which, even when employing pictorial illustrations, does so in an unimaginative and dull way using black-andwhite colouring that does not integrate the drawings with the learning input. To show these shortcomings, one only has to think of the HEADWAY or REWARD series in which illustrations are attractive and indivisible from teaching methods.

Even though pronunciation is the very first thing students encounter in their treatment of a lexeme, even long before the definitions and their various features, like most accessible things it is almost always glossed over. This neglect is the most serious because when we speak of pronunciation, we imply the actual use of language for communication. Thus students lacking proper pronunciation are the ones described by Dickerson and Finney (1988: 164, quoted in Abdullah, 1996) as ordinarily developing: "a vast passive reading vocabulary, a store of words recognized by sight. For all their store of visually recognized words, learners are often restricted in the words they can use when speaking; they must depend on words they have learned to pronounce by learning a word spoken, by looking up a word in a dictionary."

Moreover, communication itself is hampered by the incorrect pronunciation of words or failure to put stress on the right syllable. When a student knows how to say a word, it is easier for him to commit the word to memory. Yet this feature, whose immense importance we have been outlining in the above lines, hardly receives the attention it deserves: the figures are almost unbelievable in that only 13 students are for "always", and 21 for "often", compared with 93 (59\%) for "never". Pronunciation tends to be used less in this sample than it is in the studies by Bejoint (1981), Battenburg (1991) and Stein (2002). This is paradoxical, as pronunciation is a knotty area for Sudanese students who need assistance in this aspect. 
Explanations are needed for this situation and the researchers' experience as university EFL teachers guides them to the pedagogical instruction received by students as one reason. It is true that the four universities under study teach 'the phonology and phonetic courses that are the foundation of the IPA system (Gimson, 1995). However, these courses are of the strictly academic, topic -based nature, concerned with theories such as the taxonomy of vowels and consonants and the nature of the phoneme and stress. The themes become the focus in themselves and the pedagogical implications in the dictionary such as the phonemic representation in a dictionary are hardly given attention by teachers in the classroom. The result is that students cannot relate the phonology of the dictionary to their instruction in phonology courses for which this is the goal, and hence they have problems with phonetic scripts.

Now we turn to the grammatical information in its three facets of parts of speech, morphological information and syntactic patterns. Taken together, these lexical grammatical pieces of information which a dictionary provides are given in smaller and more digestible units reinforce the learning process. Our assumption is that these units will be used heavily in Sudan. However, our high expectations are dispelled in the case of the parts of speech, important for the disambiguation of words and construction of sentences. Only 11 students look them up "always", 27 "often", whilst "never" involves 53 cases. Matters are not much better for morphological information: 9 students opt for "always", 18 for "often" and 32 for "never". Finally, there are the syntactic patterns on which so much effort is exerted by lexicographers and here, again, the figures are disappointing: 9 "always", and 21 "often" in contrast to 69 "never". In the researchers' opinion, based on their young student days as constant dictionary users, there are problems with these patterns as they are time -consuming, hard to interpret and memorize, and are of questionable value. To sum up, the generally low figures for grammatical information are the more surprising if they are compared to some other Countries with an equally strong heritage of grammar teaching where grammatical information was looked up only slightly less than definitions.

There is the important feature of spelling and, indeed, for many people, spelling mistakes is a symptom of illiteracy. The fact that many English words are spelled illogically and inconsistently will probably cause confusion to EFL students when they come to write such words. For these reasons, learners have to be aware of the sources of correct spelling, and that is where the dictionary comes in since it is one of the reliable sources for spelling. For Abdullah (1996), in one of the few studies of Sudanese students' habits in handling monolingual English dictionaries, the importance of accurate spelling is particularly significant for Sudanese Arabic -speaking students who suffer from the difference between the orthography of Arabic and English, and the fact that they are required to do much coursework which is wholly written work in which faulty spelling is particularly penalized. But the figures are not the higher for the above reasons: only 36 (22\%) score "always", 16 (10\%) "often", contrasted with 54 (34\%) for "rarely" alone. The statistics for the present study are low compared to those of Bejoint (1981) and Battenburg (1991) where "spelling" scores relatively high, or Scholfield's (2002) study where spelling comes only behind meaning among the most consulted items.

Regarding collocation, it is the focus of many contemporary lexical theories of language (e.g. Lewis 1997; Cowie, 2000; Nessellhauf, 2003) stressing that no word is an island but requires the company of other words situated by virtue of its associative and syntagmatic relations. Hence, it is an inherent element of the meaning of excruciating is its collocational co- occurrence with pain, not joy or pleasure. As might have been anticipated from the overview of a parallel teachers' questionnaire together with the glimpse at the syllabi in the universities, "always" and "often" combined score merely 53 (33\%) compared with $94(59 \%)$ for the aggregate figures of "rarely" and "never". Possibly, collocation has not found its way into syntax -focused syllabi where Syntax is a primary concern of the syllabus.

There is the additional feature of the level of use which distinguishes language use according to stylistic and contextual factors along the scale of formality and specialized register domains. This feature is hardly utilized, though a course on English sociolinguistics is found in every syllabus in the four universities. Only 17 students (11\%) choose "always", 31 (19\%) "often" while 39 (24\%) go for "rarely" and 56 (32\%) opt for "never". The final aspect is the "variety of use" (statement 29(m) which indicates the distinctions such as spelling and pronunciation that are variable, mainly according to the two major dialects of British and American English. But it is equally little used: 18 (11\%) "always", and 26 (16\%) "often" in contrast to 54 (34\%) for "rarely" and 47 (30\%) for "never". 
The statistics of the use of the 13 items now gone over, a few observations are to be added. First, one might compare the optimism with which our Sudanese students viewed their knowledge of dictionaries in the opening statements of this questionnaire, the value they place upon them and their assumed competence with the actual facts of the little benefits they derive from them. In so doing, one has to agree with Bejoint (1981) who, in reviewing the optimistic findings of his predecessor Tomaszczyk (1979) who writes advanced learners seem to know all they can expect of their dictionaries and appear to be getting the most out of them, objects strongly. In contrast, Bejoint's results indicate that dictionaries are not used fully as they should be. Their introductions are not referred to, neither is the coding system and, in fine, the students are not even aware of the riches their dictionaries contain. As for the findings of the present study, we have to be even more pessimistic than Bejoint, much more pessimistic than Abdullah (1996), in the only Sudanese study of the use of monolingual dictionaries when he concludes that his students were aware of all the aspects of the dictionary, and seemed to be making good use of it. The researchers' findings point the other way: of the thirteen features covered in this part only definitions are tapped to any acceptable degree, but to the virtual neglect of almost all other aspects. This discrepancy reminds the researcher of Battenburg's (1991) comments on the tendency of EFL students to use the dictionary in a diagnostic rather than generating way, indicating the dominance of decoding functions at the expense of encoding ones.

\subsection{Students' Problems in Using Dictionaries}

\section{Table (8): Survey of Students' Problems in Using Dictionaries}

\begin{tabular}{|c|c|c|c|c|c|c|c|}
\hline Statement & & Always & Often & Sometimes & Rarely & Never & Total \\
\hline \multirow[t]{2}{*}{ a. The definitions are in difficult English } & Count & 61 & 44 & 11 & 28 & 16 & 160 \\
\hline & $\%$ & $38 \%$ & $28 \%$ & $7 \%$ & $17 \%$ & $10 \%$ & $100 \%$ \\
\hline \multirow{2}{*}{$\begin{array}{l}\text { b. It is difficult to choose among the } \\
\text { definitions. }\end{array}$} & Count & 53 & 36 & 25 & 37 & 9 & 160 \\
\hline & $\%$ & $33 \%$ & $22 \%$ & $16 \%$ & 235 & $6 \%$ & $100 \%$ \\
\hline \multirow[t]{2}{*}{ c. Definitions are not clear. } & Count & 81 & 34 & 20 & 11 & 14 & 160 \\
\hline & $\%$ & $50 \%$ & $21 \%$ & $13 \%$ & $7 \%$ & $9 \%$ & $100 \%$ \\
\hline \multirow[t]{2}{*}{ d. Entries are too long. } & Count & 56 & 27 & 13 & 45 & 19 & 160 \\
\hline & $\%$ & $35 \%$ & $17 \%$ & $8 \%$ & $28 \%$ & $12 \%$ & $100 \%$ \\
\hline \multirow[t]{2}{*}{ e. The word I am looking for is not here.. } & Count & 10 & 16 & 3 & 72 & 59 & 160 \\
\hline & $\%$ & $6 \%$ & $10 \%$ & $2 \%$ & $45 \%$ & $37 \%$ & $100 \%$ \\
\hline \multirow{2}{*}{$\begin{array}{l}\text { f. I do not understand the instructions of the } \\
\text { dictionary. }\end{array}$} & Count & 23 & 26 & 13 & 68 & 30 & 160 \\
\hline & $\%$ & $14 \%$ & $16 \%$ & $8 \%$ & $43 \%$ & $19 \%$ & $100 \%$ \\
\hline \multirow[t]{2}{*}{ g. I lack the necessary dictionary skills. } & Count & 12 & 25 & 30 & 52 & 41 & 160 \\
\hline & $\%$ & $7 \%$ & $16 \%$ & $19 \%$ & $33 \%$ & $25 \%$ & $100 \%$ \\
\hline \multirow{2}{*}{$\begin{array}{l}\text { h. I do not know how to use the right } \\
\text { dictionary for my level. }\end{array}$} & Count & 33 & 22 & 9 & 69 & 27 & 160 \\
\hline & $\%$ & $21 \%$ & $14 \%$ & $5 \%$ & $43 \%$ & $17 \%$ & $100 \%$ \\
\hline
\end{tabular}

This section investigates the students' perception of the problems they face when they look up monolinguals. Let us start with statement (a) in Table (8) above difficulty of definitions) where two- thirds of students admit to facing numerous problems - 61 (38\%) "always", 44 (28\%) "often". These problems may be due to the mismatch between the advanced level of these dictionaries and students' poor linguistic competence, on one hand, and the neglect of such components as abbreviations and the defining vocabulary, on the other. This same weakness may have bearing on statement 30 (b) (number of definitions) where, again, the percentages are high - 53 (33\%) for "always" and $36(22 \%)$ for "often". Equally, a large number of students suffer from the lack of clarity of definitions: $81(50 \%)$ "always" and 34 (21\%) "often" in contrast to only 14 cases of "never". Scores for "lengthy entries" (30 (d) are not so high but can still point to moderate problems: 56 (35\%) "always", 27 (17\%) "often", though $45(28 \%)$ decide for "rarely". Moreover, sometimes students complain about the poor content of their dictionaries (30, e) - $10(6 \%)$ "always" and $16(10 \%)$ "often" compared to a preponderance of $131(82 \%)$ for rare or absence of such incidences. However, even that meager percentage is significant, as it points to a lack of knowledge of dictionary structure, especially the location of meanings which might be widely dispersed on account of requirements of derivational morphology (personal evidence from the researchers) to sum up, our students seem to have problems with all of these dictionary aspects, the problems being mainly ascribed to the design and layout of the dictionary. 
However, a strong shift of opinion occurs in the part concerning the students' own perceptions of their shortcomings as compared to those of the dictionary. It is obvious that the students themselves are at least partially responsible for some problems encountered in the look-up process. Statement [30 (f)] suggests the neglect of instruction in the dictionary as one possible reason). However, the majority of students do not concede the presence of these problems: 23 (14\%) "always", 26 (16\%) "often", and 68 (43\%) for "rarely" alone. Another possible reason is the lack of dictionary skills [30 (g)] which is attested to by numerous studies such as that of Stein (2002), stressing that students fail to exploit the immense amount of information provided in the reference books because they lack dictionary skills. Nonetheless, this is so not perceived by our students: only 12 (7\%) go for "always", 25 (16\%) for "often", 52 (33\%) for "rarely", whilst 41 (25\%) go for "never". It is clear from items (28) and (29) that students have problems with phonetic transcriptions and, to a lesser extent, with abbreviations, i.e. those features of the macro-structure related to proper dictionary use. Finally, 30 (h) deals with the students' inability to choose a dictionary appropriate to their levels. This is already implied in the early part of this questionnaire, is strongly denied by students: 37 (23\%) "always", 22 (14\%) "often", 69 "43\%" "rarely" and 27 $(17 \%)$ "never"..It is interesting to note the sharp contrast between the students' perception of the inadequacy of dictionaries and their own assumed competence, a fact which suggests a misguided optimism. Hence, students attribute the bulk of their difficulties to the dictionary rather than their own limitations in terms of skills. This explains the presence of such things as self-reliance in dictionary purchase, aversion to guide notes, and their high rating of their abilities. Finally, it is curious to observe that the above disjunction is found elsewhere in such studies as Hartmann's (2005) in which the average for students' perception of their lack of dictionary skills is $8.09 \%$ as compared to $63 \%$ of "insufficient amount of information in the dictionary". The great contrast is also true of our own study, and suggests similarity of patterns of dictionary use worldwide.

\section{Conclusion}

The main objective of this study is to explore the myriad aspects of the attitudes and perceptions of monolingual pedagogical English dictionaries by a representative sample of Sudanese English majors. To attain this goal, the researchers have attempted to incorporate all the research procedures, operations and theoretical explorations that revolve around the questions of the study. The intention is, first, to consolidate the view of monolingual English dictionaries as a powerful aid and natural concomitant of any programme of English language teaching, an area that merits the attention of students, teachers and syllabus designers.

Particular attention has been paid to the dictionary entry, as it is the culmination of dictionary material, embodying all the information that the EFL student is expected to extract (e. g. definitions, phonology, level of use, collocations, etc.) and apply to his language activities such as reading and writing. The (11) entry components have been isolated and used as reference points in the construction of the questionnaires used in this study, To investigate the questions of the study, both quantitative and, to a lesser extent, qualitative interviews methods have been used. The 30-item questionnaire has been distributed among university English majors and designed in such a way as to probe students' opinions of dictionaries in general and EFL ones in particular concerning students' assessment of these, the frequency of the use of the dictionary entry and of the 13 established entries making up the crux of the dictionary as well as the rate of dictionary use for general rand pedagogical activities.

The statistical figures reveal that an overwhelming majority of the sample students believe that monolingual English dictionaries are the best and customary choice. Moreover, the majority of students expect dictionaries to be an indivisible part of their language programmes. This shows the importance of improving students' dictionary use capabilities. The subjects largely ignore those ancillary dictionary aspects intended to ease use, including introductions, abbreviations and the defining vocabulary. Thus, it is apparent that all students concentrate on definitions when looking up the dictionary. In conclusion, the students are more interested in denotational meaning, almost excluding other aspects like connotational meaning, level of use and pronunciation techniques.

The figures are generally disappointing and explanations might partly lie with the syllabi of the four universities under study. To start with, of the 19 courses taught at the Department of English, University of Khartoum, none explicitly mentions lexis or lexicography, for that matter. This is stark contrast to for courses devoted to Syntax, particularly the now discredited Transformational Generative Grammar. Indeed, the only related course is on Semantics, in which structural semantics embodied in such works as Lyons (1981) and Palmer (1995) are taught. As for Sudan University, out of 45 courses, the emphasis on the four language skills, excepting a course entitled "Developing Skills" which can include lexicography. 
In fact, the bulk is taken up by reading skills and writing techniques. This course has its sole parallel in Omdurman University is the first- year "Study Skills" in which the treatment of dictionaries, if any, will necessarily be sketchy and inadequate. Finally, in Al Neelein University, there is the usual disproportionate dichotomy between structural and lexical linguistics. In addition, there is the usual umbrella Study Skills course, which. Like the other universities, there is no course with the resemblance of lexicography or its cognates. It could be argued that dictionaries can be an integral part of any General English course, yet the statistics in aforementioned teachers' questionnaire reveal that only 15\% integrate dictionary skills within the General English syllabus.

Concerning the pedagogical implications of this study, it is first recommended that should exert themselves to correct the dominant notion they hold of the dictionary as yet one more passive book on the library shelf to be resorted to in time of need. Also, lexicography should be taught thoroughly and consciously as an integral part of the English language syllabus and not a mere addendum. Moreover, such coverage should include interactive lexicography that goes beyond paper-based versions to encompass accompanying electronic versions (of e.g. OALD on CD-ROM) and internet online dictionaries to provide learners with the versatility and stimulation of these up-to-date sources. Equally, there must be an inclusion of task-based activities in General English lessons to provide the learners with the means to handle the facets of monolingual dictionaries such as definitions, pronunciation and collocations.

\section{References}

Abdullah,S.A.(1996).Investigating Sudanese EFL Learners' Monolingual Dictionary Awareness. Unpublished M.A. Thesis. University of Khartoum, Sudan.

Ahmed, M.O. (1994). Vocabulary Acquisition: A Study of Habits. Khartoum University Press.

Al-Busairi, M. (2002). Situation of English at the Tertiary Level. Khartoum: Sudanow. April Issue.

Ali, N. and Siddiek, A. (2013). Exploring English Language Teachers' Attitudes Towards Using Pedagogical Dictionaries; A Sudanese Perspective. International Journal of Applied Linguistics and English Literature, 3(3): 171- 188.

Atkins, B.T. et al. (1985). The Dictionary and the Language Learner. Niemeyer: Tübingen

Atkins, B. T. (ed.,). (1998). Using Dictionaries: studies of dictionary use by language learners and translators. Niemeyer: Tübingen.

Baxter, J. (1980). The dictionary and vocabulary behavior: a single word or a handful? TESOL_Quarterly XIV. 3.325-336.

Battenburg, John. (1992). English Monolingual Learners' Dictionaries: A User-Oriented Study. Lexicographica, Series. Major 39. Tübingen, Germany: Niemeyer Press.

Bejoint, H. (1981). The foreign students' use of monolingual English dictionaries: A Study of language needs and reference skills Applied Linguistics, 3: 207- 222.

Benoussan, M., Sim, D. and Weiss, R. (1984). The effect of dictionary usage on EFL test performance compared with student and teacher attitudes and expectations. Readings in a Foreign Language 2.262-276.

Braima, M.A. (2004). Situation of English Language Post - Arabicisation. Unpublished Ph.D. Thesis. University of Malaya, Kuala Lumpur, Malaysia.

Chomsky, N. (1957). Syntactic Structures. The Hague: Mouton.

Chomsky, N. (1965). Aspects of the Theory of Syntax. Cambridge, Massachusetts, MIT Press.

Coogan, M. D, (Ed). (2001). The New Annotated Oxford Bible. New York: Oxford.

Cowie, A.P. and Howarth, P. (2000). Phraseological Competence and Written Proficiency. In G.M. Blue and R. Mitchell (eds.), Language and Education. Oxford: Oxford University Press.

Crystal, D. (2003). English as a Global Language. Cambridge: Cambridge University Press.

Garcia, M. (2005). Using Monolingual English Dictionaries for Soluton of Lexical Problems of Mexican Students. Unpublished Ph.D. Thesis: University of Essex.

Gimson, A.C. (1995). An Introduction to the Pronunciation of English. London: Arnolds.

Hartmann, R.R.K. (1991). What is the Use of Learners' Dictionaries? Institute of Language in Education Journal.

Hartmann, R.R.K. (2002). Thematic Network Project in the Area of Languages. Subproject 9: Dictionaries. Exeter. 
Hartmann, R.R.K. 2003). Lexicography with particular reference to English learners' dictionaries. Language Teaching. 25. 151-59.

Hartmann, R.R.K. (1994). The Learners Dictionary: Unilingual or Interlingual? In L. Flowerdew and K.K. Tong (eds.) Entering Text. Hong Kong: The Hong Kong University.

Hartmann, R.R.K. (20o5). Dictionaries and their Users. Exeter: University of Exeter.

Hornby, A.S. (2010). Oxford Advanced Learners' Dictionary ( ${ }^{\text {th }}$ ed.). Oxford: Oxford University Press.

Howard, N. (2008). An Interview- based Study of the Functions of Citations across two Disciplines. Journal of Pragmatics (a pre- print).

Hupka, W. (1995). Word and Picture: Illustrations in Dictionaries and Encyclopedias. Tübingen: Niemeyer.

Kiefer, B. (1994). Methods of ordering senses within entries. In L. Fiowerdew and K. K. Tong. (eds.)

Landau, S.I. (1989). Dictionaries: The Art and Craft of Lexicography. New York: C. Scribner and Sons.

Lewis. M. (1997). Implementing The Lexical Approach. Rove: Language Teaching Publications.

Lyons, J. (1981). Language and Linguistics. Cambrdge: Cambridge University Press.

Lyotard, F. (1997). The Postmodern Condition: An Essay on Knowledge. Francisco University Press.

Nakamura, M. (2003). The use of the electronic IC dictionary in the EFL environment. In M. Murata,S. Yamada, \& Y. Tono (Eds.), Proceedings of the 3rd ASIALEX Biennial International Conference(pp. 346-350)

Nation, I. S. P. (2001). Learning vocabulary in another language. Cambridge: Cambridge University Press.

Palmer, F.R. (1995). Semantics (2nd edition). Cambridge: Cambridge University Press.

Raudaskoski, S. (2002). Translation, the Key or the Equivalent?, Kemerman Dictionary News, No. 10. [Retrieved January 17, 2014, from http://kdietionaries.ronilnewrletterlkdnI 0-10.htrnl].

Sandell, L. (1982). English Language in Sudan: A History of its Teaching and Politics. Ithaca Press: London.

Schmitt, N. (2007). Vocabulary in Language Teaching. Cambridge: Cambridge University Press.

Scholfield, P. (1982).Using the Dictionary for Comprehension. TESOL Quarterly 16.2: 185-194.

Scholfield, P. (2002). Why Shouldn't Monolingual Dictionaries be as Easy to Use as Bilingual Ones? [Retrieved April 23,2014, from httpi/www .logman.coml dirtionaaies/tearherr/articles/p-rcholfield- 02. htndj.

Sinclair, J. (ed.,). (1995). Looking-Up. An AcCount of the COBUILD Project in Lexical Computing and the Development of Collins- COBUILD English Language Dictionary. London: Harper Collins.

Stein, G. (1990). From the Bilingual to the Monolingual Dictionary. Hamburg University.

Stein, G. (1995). Illustration in Dictionaries. International Journal of Lexicography 4.2: 99-127.

Stein, G. (2002). Better Words: Evaluation of EFL Dictionaries. Exeter: Exeter University Press.

Tomaszczyk, j. (1979). Dictionary Users and Uses. Glottodidactica, 12: 103:119.

Wright, J. (2001). Dictionaries, Resource Books for Teachers, Oxford University Press, Oxford. 